\title{
Jumbosize Europe? European Union conference on obesity calls for immediate action*
}

\author{
Anne Raben \\ Department of Human Nutrition, Centre for Advance Food Studies, The Royal Veterinary and Agricultural University, \\ Copenhagen, Denmark; SNF, Swedish Nutrition Foundation, Ideon Research Park, Lund, Sweden
}

\section{Abstract}

The average prevalence of obesity in Europe is now $15-20 \%$, with increasing rates in most countries. The prevalence of both overweight and obesity is as high as $50-65 \%$, and childhood obesity is also increasing at an alarming pace. The epidemic has been followed by a simultaneous rise in type II diabetes. Action is therefore urgently needed. This was stressed at a European Union (EU) conference on obesity held in September 2002 in Copenhagen. Our environment favours a high energy intake and a low energy expenditure, both conducive to weight gain. We must therefore change the environment and our behaviour to increase leisure-time physical activity and decrease the intake of fat-rich, energy-dense foods and drinks, e.g. by improved traffic planning, more physical activity in schools, differentiated taxes on foods and drinks, and banning of commercials for unhealthy foods. There is an urgent need for public health programmes, training of health professionals and collaboration with the food industry. Prevention of overweight in children should be given high priority. A first sign of willingness to act has appeared: in December 2002 the Council of the EU adopted a number of conclusions on obesity put forward by the Danish EU Presidency as a result of this conference.

Keywords: Children; diet; exercise; overweight; prevention; treatment

\section{Introduction}

In September 2002, a European Union (EU) conference on obesity was held by the Danish EU Presidency in Copenhagen, Denmark. Leading experts in obesity as well as European chief medical officers, permanent secretaries, national government representatives, and policy planners from health promotion and prevention units were invited. The purpose was to present the state of the art and to facilitate and develop a broad, integrated and crosssectoral view of the problem. Furthermore, it was an opportunity to discuss the possibilities for national and EU co-ordinated strategies to place

\footnotetext{
*The talks and presentations at the conference were given by Lars Løkke Rasmussen, Jens Kr. Gøtrik, Fernand Sauer, Jacob Seidell, Stephan Rössner, Arne Astrup, Aila Rissanen, Jaakko Tuomilehto, Philip James, Finn Skaarderud, Anne Raben, Berit Heitmann, Mikael Fogelholm, Bernard Gyu-Grand, Ole Lander Svendsen, Vojtech Hainer, Moira A. Taylor, Marie-Laure Frelut, Carl Erik Flodmark, Tim Cole, Kim Fleischer-Michaelsen, Bjørn Richelsen, Peter Kopelman, Imogen Sharp, James Hill and Thorkild I. A. Sørensen. Reports from the conference can be found at www.obesity.dk. The wording in this review is entirely the responsibility of the author.
}

obesity high on the political agenda. Decision makers from a total of $22 \mathrm{EU}$ and candidate countries plus Norway and Iceland were represented. This paper summarizes and elaborates on the presentations and discussions at the conference.

\section{The obesity epidemic}

We are facing an obesity pandemic, not only in Europe, but in many parts of the world. The escalating pace with which the increase obesity has occurred during the past 20 years is terrifying. The average prevalence of obesity in Europe is now 15$20 \%$ (Table 1), corresponding to at least 60 million Europeans. If considering both overweight and obesity, the prevalence is as high as $50-65 \%$, or at least 200 million Europeans. This means that it has become normal to be overweight and that in some countries only one-third of the population is still normal weight. In the USA the prevalence of overweight and obesity is $61 \%$ and the figure for obesity is as high as $27 \%$. It is estimated that Europe is only 5 years behind the USA, so the US levels will 
Table I. Classification of overweight and obesity in adults according to body mass index (BMI) (I)

\begin{tabular}{lll}
\hline Classification & BMI $\left(\mathbf{k g ~ m}^{-\mathbf{2}}\right)$ & Risk of obesity comorbidities \\
\hline Underweight & $<18.5$ & $\begin{array}{l}\text { Low (but risk of other clinical } \\
\text { problems increased) } \\
\text { Average }\end{array}$ \\
Normal range & $18.5-24.9$ & Mildly increased \\
Overweight (preobese) & $25.0-29.9$ & \\
Obese & $\geq 30.0$ & Moderate \\
Class I & $30.0-34.9$ & Severe \\
Class II & $35.0-39.9$ & Very severe \\
Class III & $\geq 40.0$ & \\
\hline
\end{tabular}

soon be reached unless some dramatic changes are made.

There are quite large gender as well as regional differences in prevalence rates in Europe. In men the highest prevalence rates ( $\geq 70 \%$ overweight and obese) are seen in Germany and Greece, the Czech Republic and Malta (Fig. 1) (2). The lowest rate in men is seen in France $(43 \%)$. In no country is the prevalence of overweight and obesity in men below $40 \%$. In general, women have lower prevalence rates than men. The highest figures $(\geq 60 \%)$ are observed in Greece and the UK, Malta and former East European countries. The lowest rate for women is seen in France (27\%) (Fig. 1). It was stated several times during the conference that if one could find the reason for the regional differences in obesity in Europe, one might find a way to combat obesity.

Besides regional and gender differences, lower social class and lower educational level are associated with higher degrees of obesity. At the same time it is known that once a person is obese, it is more difficult for them to rise in socioeconomic status. This may be due, among other things, to less favourable job opportunities and lower self-esteem. Obesity is therefore a social problem that both results from and contributes to social inequalities.

Children are also struck by the obesity epidemic. In the UK, $15 \%$ of 9-11-year-old children were overweight or obese in 1994. Cut-off limits for overweight and obesity in children were described by Cole et al. in 2000 (3). The latest figures from 1998 show, however, that this has increased to $22 \%$ in the UK (Fig. 2), giving an increase of 50\% in 4 years (2). Based on this dramatic rise, the present prevalence of overweight children in the UK may be as high as $30-35 \%$. The latest data from Europe by the International Obesity Task Force (IOTF), cover- ing the period 1995-2001, show that the average prevalence of overweight in European children around 10 years of age is about $20 \%$ (range $10-$ $36 \%$ ). The highest prevalence rates ( $>30 \%$ overweight) were seen in the Mediterranean countries, Italy, Malta, Greece and Spain. The lowest prevalence rates $(<15 \%)$ were seen in Slovakia, Finland and the Netherlands. Denmark and Sweden had a prevalence of overweight and obese children of $18 \%$ and Norway of $21 \%$.

Childhood obesity will often lead to adult obesity. Thus, it has been shown that in adults who are more than $160 \%$ overweight, $50-75 \%$ were overweight as children. In addition, for 5-10-y-old children, the risk of becoming overweight is much larger when both parents are overweight. Diet and exercise habits are often formed during childhood. Action against childhood obesity must therefore be given very high priority.

Although the above prevalence rates for overweight and obesity are already very high, they may be even higher in real life. Most data on body weight and height are based on self-reported (subjective) values and people tend to underreport their weight and overreport their height. This can lead to an underestimation of the prevalence of overweight by as much as $50 \%$ compared with measured (objective) values (4).

\section{Consequences of obesity}

Obesity is the most important known risk factor for type II diabetes. Thus, data from the Nurses' Health Study showed that obese women [body mass index $(\mathrm{BMI}) \geq 30.0 \mathrm{~kg} \mathrm{~m}^{-2}$ ] had a 20 times higher risk of developing type II diabetes than did lean women $\left(\mathrm{BMI}<23.0 \mathrm{~kg} \mathrm{~m}^{-2}\right.$ ) (Table 2) (5). Obesity gives also rise to other serious complications such as cardiovascular diseases, hypertension, certain cancers (particularly in the breast and colon) and psychosocial problems (e.g. depression, anxiety, loneliness, discrimination and bullying). Further health consequences of obesity are dyslipidaemia, insulin resistance, osteoarthritis, sleep apnoea, asthma, lower back pain, gallbladder disease, abnormalities of reproductive hormones, polycystic ovarian syndrome and impaired fertility. Last but not least, childbirth is jeopardized owing to a larger birth weight when the mother is obese. This may increase the risk of injuries and even suffocation of the child during delivery. 
(a)

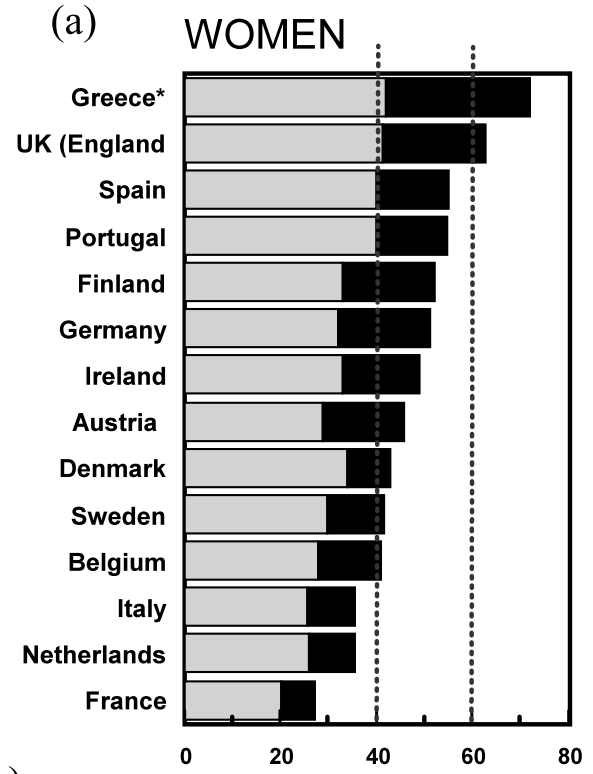

(b)

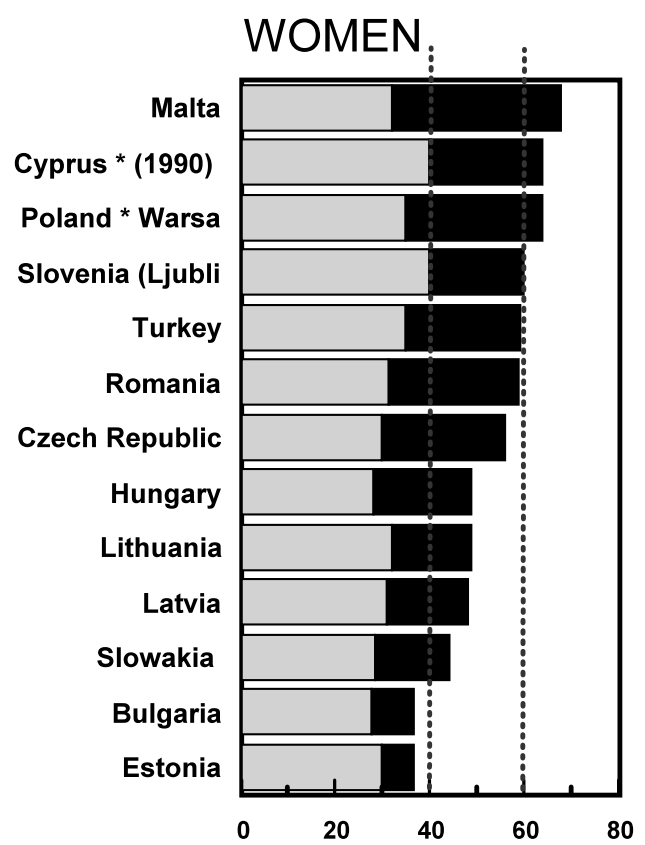

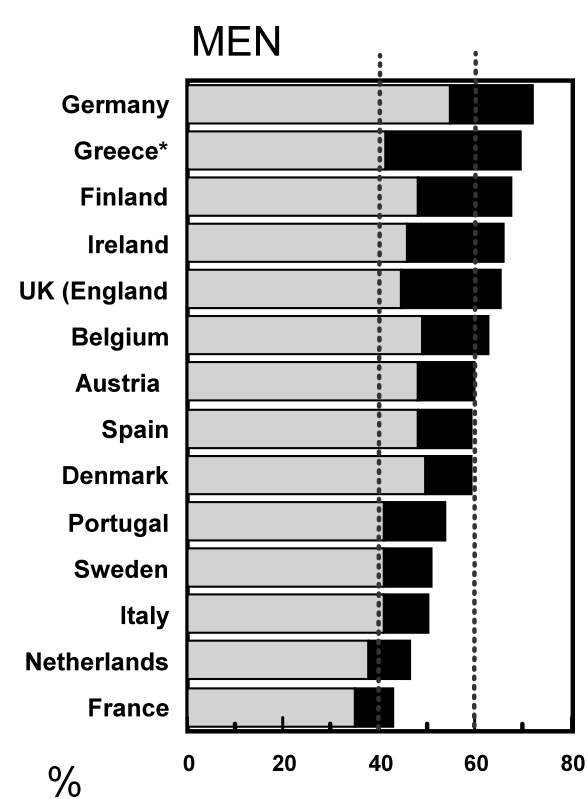

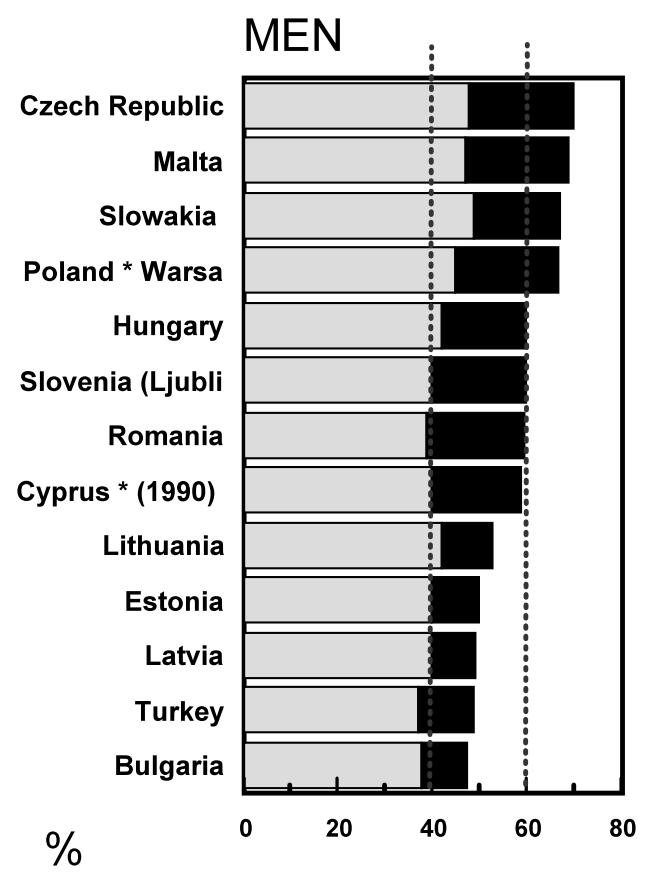

Fig. 1. Estimated relative prevalence of overweight and obesity in (a) the European Union (EU) member states before December 2002; and (b) the new EU and accession countries in December 2002. * Restricted age group. Black: obese [body mass index $(\mathrm{BMI}) \geq 30.0 \mathrm{~kg} \mathrm{~m}{ }^{-2}$ ]; grey: overweight (BMI $\geq 25.0 \mathrm{~kg} \mathrm{~m}^{-2}$ ). [Reproduced with permission from the International Obesity Task Force and European Association for the Study of Obesity Task Forces (2).]

Different types of overweight and obesity are not equally unhealthy. Thus, abdominal adiposity (typically male adiposity) is more threatening to health, owing to the high lipolytic activity in this tissue, compared with subcutaneous adipose tissue or adipose tissue on the hips and thighs (typically female adiposity).

The social costs of obesity are now being compared with those of smoking. Obese people have far more workdays lost through illness than lean people. Owing to the consequences on health and employment the economical consequences of obesity are large. It is estimated that the costs amount to up to $8 \%$ of overall health budgets.

\section{Reasons for the obesity epidemic}

The reason for an increase in body weight and fat mass is a positive energy balance, arising from an 


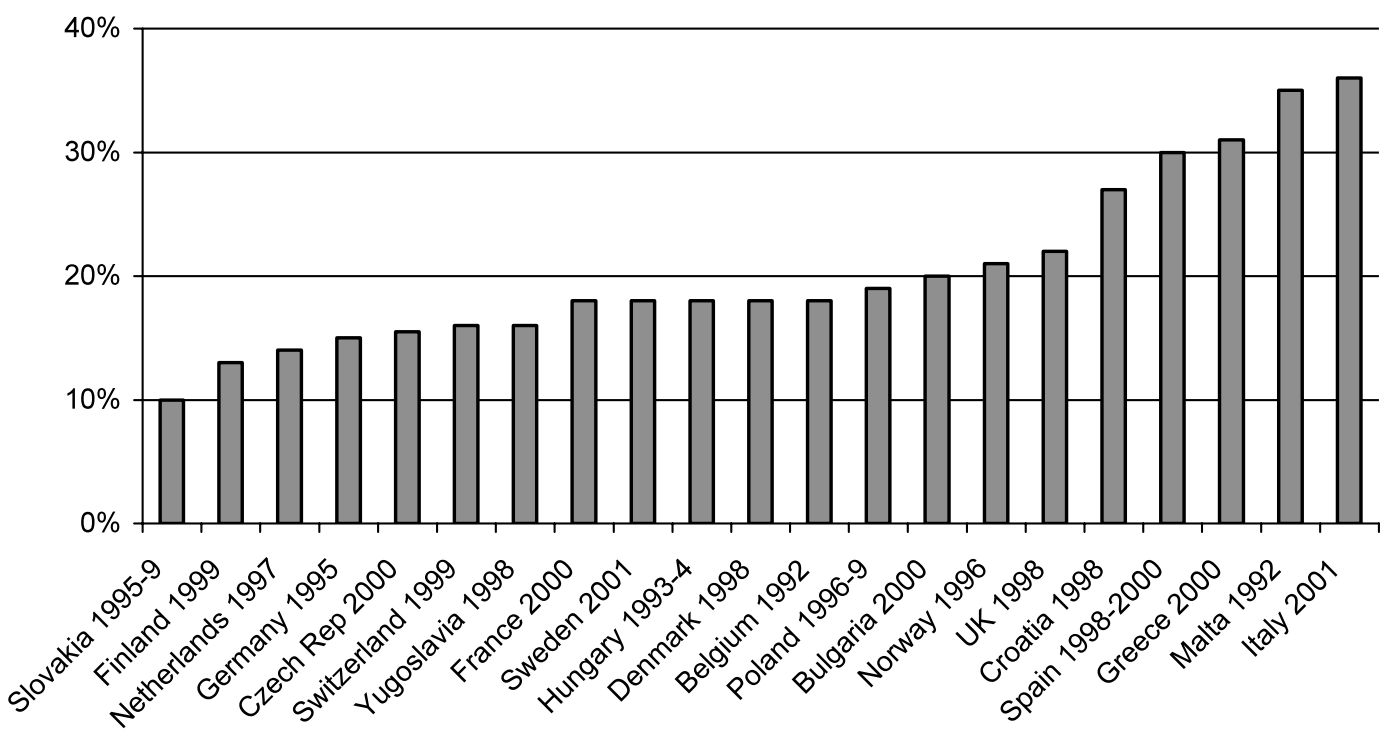

Fig. 2. Prevalence of overweight in children around $10 \mathrm{y}$ of age. Overweight in children corresponds to body mass index $>25 \mathrm{~kg} \mathrm{~m}{ }^{-2}$ at 18 years of age using the International Obesity Task Force assessment method (see Ref. (3)). [Reproduced with permission from the International Obesity Task Force and European Association for the Study of Obesity Task Forces (2).]

Table 2. Relative risk of type II diabetes among 884941 women (5) (Nurses' Health Study, 1980-1996)

\begin{tabular}{ll}
\hline Risk factor & Relative risk \\
\hline Body mass index $\left(\mathrm{kg} \mathrm{m}^{-2}\right)$ & \\
$\quad<23.0$ & 1.0 \\
$23.0-24.9$ & 2.7 \\
$25.0-29.9$ & 7.6 \\
$30.0-34.9$ & 20.1 \\
$\geq 35.0$ & 38.8 \\
Quintile for dietary scores & \\
I: least "healthy" & 1.0 \\
3 & 0.8 \\
$5:$ most "healthy" & 0.5 \\
Weekly exercise & \\
$<0.5 \mathrm{~h}$ & 1.0 \\
$2.0-3.9 \mathrm{~h}$ & 0.9 \\
$\geq 7.0 \mathrm{~h}$ & 0.7 \\
\hline
\end{tabular}

increase in energy intake and/or a decrease in energy expenditure. It is most likely, that both sides of the energy balance are involved in the present obesity epidemic. Obesity is, however, a complex problem derived from a complexity of factors e.g. genetic, social, behavioural and cultural, as well as interactions among these factors.

\section{Genes}

Genetic predisposition to obesity is normally attributed to about one-third of the cases of obesity. Since our genes have not changed during the past 20 years this cannot, however, explain the obesity epidemic observed during the same period. Instead, the reason must be found in changes in lifestyle factors, i.e. diet and physical activity. There seems to be a mismatch between our genes and the environment. Our genes tell us to eat when there is food available, and to rest when we do not have to be physically active. This strategy has helped us to survive throughout time, but today it has become life threatening. In Western societies food is always available and modern technology has replaced physical activity. Therefore, both the environment and behaviour of people must be changed to combat obesity.

\section{Environment and behaviour}

Although it is the individuals' behaviour that determines energy input and output, people live in environments that facilitate certain behaviours.

\section{Physical activity}

First, it is difficult not to have a sedentary lifestyle in modern society. In general, physical activity is only undertaken by the few and most often in an organized manner (e.g. sports clubs). Most people do not need to walk or cycle to work or elsewhere, but can go by car or public transportation to most destinations. People even use the car for very short distances. Data from Finland showed that for distances of $2 \mathrm{~km}$ or above the car was the most 


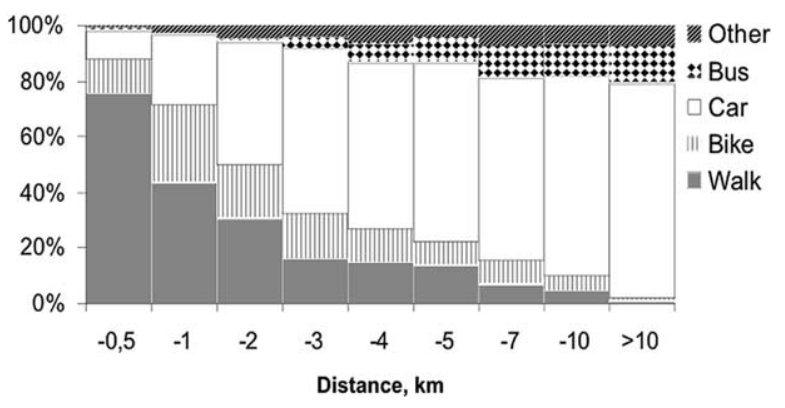

Fig. 3. Data from a Finnish report on transport and communications showing how different means of transport are used according to distance. The car is used most often, even for short distances $(<2$ km). [From Passenger Transport Survey 1998-1999 (6).]

used means of transportation (Fig. 3) (6). In some countries (e.g. the USA) and cities (e.g. Paris) it is even considered dangerous to walk or cycle and there is a lack of pavements and cycle lanes. In other countries (Sweden, Denmark, the Netherlands) the situation is much better, but even here a reduction in cycling and walking is being observed. It is now quite normal for children to be driven to school in cars by their parents. This creates a situation where it is less safe for other children to walk or cycle, and a vicious circle is created.

Another example is escalators. In public places and hotels escalators and lifts are placed in the prime position in the building, whereas staircases are located far away, sometimes hard to find and regarded as emergency routes only. This promotes a behaviour of low physical activity.
A third example, which combines both low physical activity and snack eating, is television. The television became popular in the 1960s, since when people have become more and more obese. The use of televisions (often as babysitters), video games and computers, especially by children sitting for hours a day, takes time away from physically demanding activities, such as playing outdoors and participating in sports.

In a sample of 15239 men and women from the 15 EU member states (before 2003), obesity and higher body weight were strongly associated with a sedentary lifestyle and lack of physical activity. The odds of being obese were increased three to four times in those who were most sedentary in their leisure time (two lower quintiles of physical activity and two upper quintiles of hours per week spent sitting down) (Fig. 4) (7). Although these results are cross-sectional and therefore should be interpreted with some caution, they do support the theory that reduced energy expenditure through less leisure time activities is involved in the obesity epidemic.

\section{Food intake}

From a physiological point of view, it is easier to overconsume than to underconsume energy. We have no strong alarm signals to tell us that we have eaten too much energy, but we have strong feelings of hunger and dissatisfaction if we do not eat. Therefore, given the abundance of energy-dense foods and drinks available, it takes an active effort

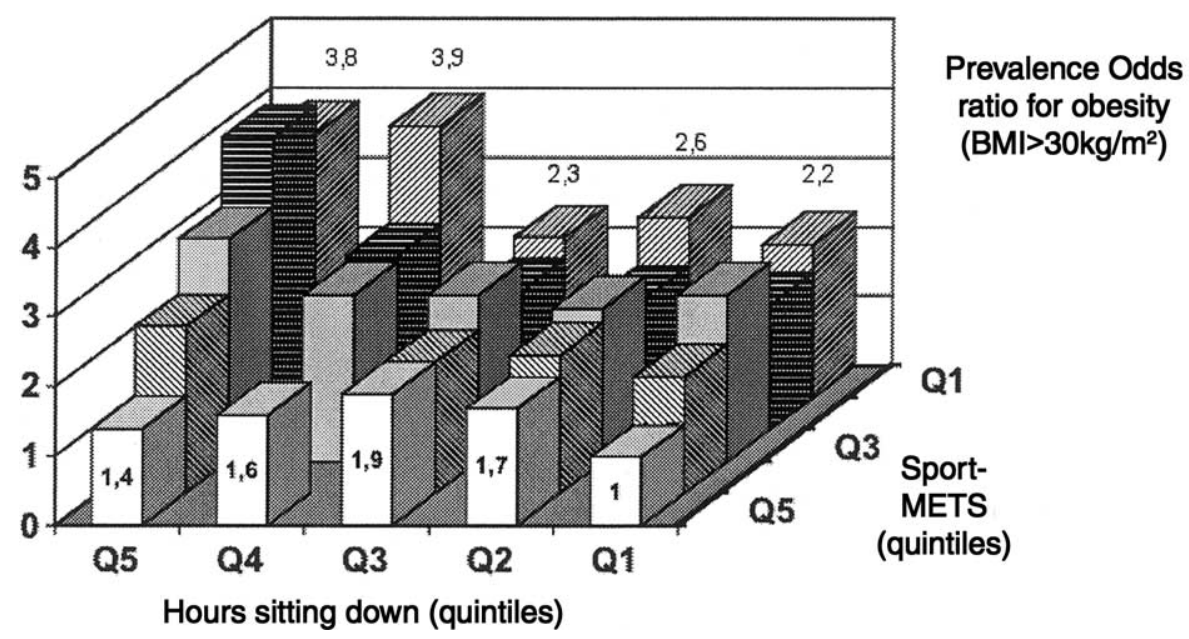

Fig. 4. Classification of a sample of 15239 from the 15 European Union member states (before 2003) according to quintiles of hours sitting during leisure time on the left axis, and leisure-time physical activity. For each combination of time sitting down and sport-METS (metabolic equivalent score), the adjusted prevalence odds ratio for obesity (body mass index $>30 \mathrm{~kg} \mathrm{~m}^{-2}$ ) is presented with reference to the category with the highest energy expenditure (sport-METS Q5 $>30)$ and shortest time spent sitting down $\left(\mathrm{Q} 1<15 \mathrm{~h} \mathrm{week}^{-1}\right)$. [Reproduced with permission from Martinez-Gonzales et al. (7)]. 
not to consume more calories than the body needs. An increase in energy intake is promoted by the intake of fat-rich, energy-dense, low-carbohydrate and low-fibre diets, combined with a high intake of sugar-rich drinks (Table 3). The latter was demonstrated in a recent intervention study in overweight healthy subjects, which showed that intake of about 1.3 litres day ${ }^{-1}$ of sugar-rich drinks increased body weight, fat mass and blood pressure after 10 weeks compared with artificially sweetened drinks (Fig. 5) (8). Furthermore, portion sizes, especially of many fast foods, have increased to almost grotesque sizes. Recent data from the USA have shown an average increase in energy intake of $11 \%$ or $195 \mathrm{kcal} \mathrm{day}^{-1}$ in 20 years (Table 3) (9). Not all data from European countries show such an increase in energy intake, however.

\section{Other factors}

Medication, smoking cessation and pregnancy are all conditions that can promote weight gain. The most important factor in weight retention after pregnancy is weight gain, especially during the first part of the pregnancy, but smoking cessation before or during pregnancy is also a contributing factor. Regarding smoking cessation, $80 \%$ of quitters experience a weight gain within 2 years from cessation, and $20 \%$ experience a weight gain of more than $5 \mathrm{~kg}$. However, after 10 years the average body weight of ex-smokers is similar to that of people who have never smoked. The weight gain is therefore not sustained in the long term, and the health benefits of smoking cessation should still be promoted. Drugs that can induce weight gain include glucocorticoids, antipsychotics, antidepressants, antimigraine drugs, sex hormones, antihistamines, $\beta$-blockers and antidiabetic agents.

Table 3. Trends in energy intake (kcal) in the USA $(n=63380)$ (9)

\begin{tabular}{llccc}
\hline Age group & & $1977-1978$ & $1994-1996$ & Difference \\
\hline $2-18$ years & Meals & 1600 & $1549^{* *}$ & $-3 \%$ \\
& Snacks & 240 & $409^{* *}$ & $+50 \%$ \\
& Total & 1840 & $1958^{* *}$ & $+7 \%$ \\
\multirow{2}{*}{$40-59$ years } & Meals & 1572 & $1632^{* *}$ & $+4 \%$ \\
& Snacks & 175 & $323^{* *}$ & $+85 \%$ \\
& Total & 1747 & $1954^{* *}$ & $+12 \%$ \\
All, age $\geq 2$ years & Meals & 1588 & $1634^{* *}$ & $+3 \%$ \\
& Snacks & 203 & $351^{* *}$ & $+73 \%$ \\
& Total & 1791 & $1985^{* *}$ & $+11 \%$ \\
\hline
\end{tabular}

** Significantly different from 1977-1978 ( $p \leq 0.01)$.

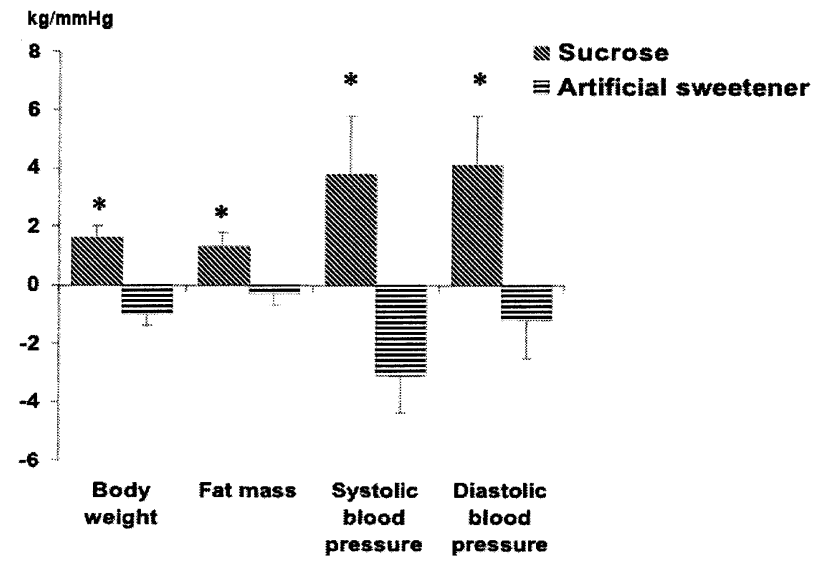

Fig. 5. Mean $( \pm$ SEM) change in body weight, fat mass, systolic and diastolic blood pressure in overweight subjects (mean body mass index $27.8 \mathrm{~kg} \mathrm{~m}^{-2}$ ) after 10 weeks of ad libitum diet with high amounts of primarily drinks, containing either sucrose $(n=21)$ or artificial sweetener $(n=20)$. * Significantly different from artificial sweetener $(p<0.05)$. (Data extracted from 8$)$.

\section{Means to combat the obesity epidemic}

Both behaviour and environment must change to acquire healthy habits concerning diet and physical activity. The means are very similar to those needed to combat diseases such as type II diabetes, cardiovascular diseases, and breast and colon cancer. Therefore, joint efforts are possible and even recommended. Although we do not know everything yet, enough is known to initiate actions and we cannot afford to wait. Logical thinking and positive results already achieved must form the basis of these actions. As well as approaching the public at large, high-risk individuals must be targeted.

\section{Treatment or prevention?}

Obesity is difficult to treat with permanent longterm weight loss. This makes prevention an important goal. However, the millions of adults and children who are already obese cannot be abandoned. Therefore, treatment and prevention should go hand in hand. This makes sense, since many of the necessary actions and measures apply to both measures. In the UK, a twin-track approach has already been launched. Track 1 is "prevention", considered the best long-term strategy, and track 2 is "cessation", i.e. treatment and management, diet, physical activity, behavioural interventions, drug therapy and surgical interventions.

An overall change in lifestyle behaviour has been proven to be very efficient in achieving a significant weight loss. In the Finnish Diabetes Prevention Study, 522 subjects (mean BMI $31 \mathrm{~kg} \mathrm{~m}^{-2}$ ) with 
impaired glucose tolerance were randomized into two groups. The intervention group received intense individual advice to reduce weight, intake of energy, total fat $(<30 \mathrm{E} \%)$ and saturated fat $(<30 \%$ of all fats), and to increase dietary fibre $(>15 \mathrm{~g} 1000$ $\mathrm{kcal}^{-1}$ ) and physical activity $\left(>4 \mathrm{~h}\right.$ week $\left.{ }^{-1}\right)$. The control group also received advice on healthy lifestyle, but only at randomization and at the annual follow-up visits. After 1 and 2 years the weight loss was 4.2 and $3.5 \mathrm{~kg}$ in the intervention group compared with 0.8 and $0.8 \mathrm{~kg}$ in the control group, respectively. The cumulative incidence of diabetes was reduced by $58 \%$ and more favourable changes in all anthropometric and metabolic parameters were observed in the intervention compared with the control group. Hence, this controlled, randomized study among individuals with a high risk of diabetes demonstrated that type II diabetes can be effectively prevented by a reinforced lifestyle intervention programme producing weight loss. A reduction in diabetes risk of $58 \%$ was also recently achieved in a similar study in the USA.

\section{Prevention}

The target areas for prevention of obesity, many of which are also relevant in the treatment of obesity, include:

- town, housing and traffic planning: e.g. more and better pavements, bicycle lanes and increased traffic security

- schools and work places: more hours of physical activity in schools, during and after school hours; possibilities, encouragement and breaks for physical activity at work; weight-loss classes at work

- leisure-time activities: more recreational areas. building and financial support for indoor and outdoor exercise facilities

- legal initiatives and regulations: improved nutrient information; symbols for foods living up to dietary recommendations; banning of commercials for unhealthy foods and drinks

- financial regulation: subvention for products with low fat and energy density, fruit and vegetables; taxes on high-fat foods; support for dietetic counselling and for research in methods to prevent overweight and obesity

- dietary politics: compliance with dietary recommendations at nurseries, schools, workplaces, exercise clubs, etc.; prohibition of vending machines with snack foods and drinks
- education and training: teaching in healthy diet and exercise habits in schools, for caretakers, teachers and health professionals (nurses, doctors, dieticians, dentists); courses for high-risk children and adults

- information: spreading the healthy diet and exercise message by mass media and the internet

- food industry: increased responsibility for producing non-fattening products and for collaboration with the health community.

\section{Foods and drinks}

Several intervention studies and meta-analyses support the theory that a high-carbohydrate, low-fat diet produces a spontaneous reduction in energy intake, body weight, fat mass and risk factors for type II diabetes and cardiovascular diseases (10). High-protein, low-fat diets can also produce weight loss. Effective means of reducing energy intake include a decrease in fat intake (all fats) to below $30 \%$ of energy, an increase in carbohydrate intake (at least $50-55 \%$ of energy), primarily from wholegrain cereals, pasta, rice, vegetables and fruit, an increase in protein intake (15-20\% of energy) from low-fat meat, fish and milk products, a decrease in high-energy drinks and a general decrease in portion sizes (Table 4).

Since purchase is often governed by the price of foods, foods and drinks should be subject to differentiated taxes. Thus, a reduction in taxes on vegetables and fruit (fresh, and frozen but otherwise unprepared) and wholegrain products would increase the sale of these foods. Extra taxes could be added to fatty foods and sugar-rich drinks instead. Such suggestions have been put forward in both Denmark and Sweden, but politicians have so far

Table 4. Dietary factors involved in body weight regulation

\begin{tabular}{ll}
\hline $\begin{array}{l}\text { Promoting increased energy } \\
\text { intake and weight gain }\end{array}$ & $\begin{array}{l}\text { Promoting decreased energy } \\
\text { intake and weight loss }\end{array}$ \\
\hline High-fat foods & High-carbohydrate foods \\
Energy-dense foods & High-fibre foods \\
Calorie-containing drinks & High-protein foods \\
Large portion sizes & Non-caloric drinks \\
High palatability & Fruit and vegetables \\
Low cost & High cost \\
\hline
\end{tabular}

There is no evidence yet that different types of fats, carbohydrates or proteins have different effects on long-term body weight regulation. 
argued against them, claiming that they would be too administratively expensive. The question is whether it is not much more expensive to let the obesity epidemic continue, considering the enormous cost to the national budget, to the affected individuals and to the entire society.

A survey in Denmark in 2001 showed that about $85 \%$ of all commercials for children promoted sweets or similar products with a high fat and/or sugar content. This is likely to create an unnecessary and unwanted need for these products. Commercials on foods and drinks that do not comply with dietary recommendations should therefore be banned on television, whenever possible. Instead, programmes and news items should promote the benefits of a healthy diet and exercise and give practical advice.

Schools are becoming increasingly influenced by manufacturers of soft drinks and snacks (chocolate, crisps, etc.). Manufacturers make substantial financial contributions to schools if their vending machines are placed centrally in the schools. Children are therefore tempted to buy these products instead of proper food for their meals. This phenomenon is a real problem in the USA, but is now also occurring in Europe. Support for good school lunches is therefore important.

Finally, health claims on foods that do comply with the recommendations should be allowed. This is already the case in some countries (e.g. Sweden, the Netherlands, the UK), but not in others (e.g. Denmark).

\section{Education}

It is important to train health professionals. Practitioners should give patients a dietary check-up besides a physical examination at regular intervals. This could be done in collaboration with a dietician. The information will both enlighten the patient about his or her diet, and give warning signals about unhealthy eating habits before the effects on health appear. Likewise, a questionnaire about physical activity should be obligatory. Physical activity is not only important in weight management, but also beneficial in relation to insulin sensitivity, the strength of skeletal muscles and joints, and mental health.

\section{Breast-feeding}

Data from studies in 12-18-y-old children have shown that breast-feeding protects against becom- ing obese. Further, it has been shown that the larger the quantities of breast milk consumed, the leaner the children are at the age of 1-2 years. It has been proven that overweight mothers are less successful in breast-feeding. This may result from mechanical problems, but also the educational and social status of the mother. In Scotland, mothers have been discouraged from breast-feeding in public places. This has, in part, been blamed for the low rate of breast-feeding of only $29 \%$. A new law has, however, been passed making it illegal to discriminate against breast-feeding mothers.

Breast-feeding should be promoted, owing to its possible protective effects on overweight as well as its other positive effects (e.g. on the immune system and intelligence quotient). Four goals are stated in the Innocenti Declaration: (i) appointment of a national breast-feeding co-ordinator and committee; (ii) implementation of the Baby Friendly Hospital Initiative; (iii) implementation of the International Code of Marketing for Breast Milk Substitute; and (iv) legislation that supports working mothers and extended maternity leave (11).

\section{Food industry}

The food and drink industry has a major responsibility in taking action against obesity. At the same time, researchers and the public should stop regarding industry as the villain. Fruitful collaborations between universities and industry are already taking place, showing that at least some industries are interested in producing healthy products. However, an even closer and more extended collaboration is needed between food industry and the public health community.

\section{Treatment}

Apart from the actions to prevent obesity, which also apply to treatment, specific action must be taken to treat those who are already obese. These include weight loss induced by very low-calorie diets (VLCD), typically different protein-powders, drugs or surgery. In most European countries, there is a need to establish comprehensive obesity management programmes including dietary management, physical activity, behaviour modification, drug treatment and bariatric surgery. Involvement of the community in planning and delivery of the programmes is important. No health-care system can, however, afford to treat all obese patients, so self-assessment and self-management through, for 
instance, textbooks, the internet and mass media are required.

At present, practices vary greatly around Europe. A recent survey in 24 European countries conducted by the European Association for the Study of Obesity (EASO) showed that the involvement of the general practitioner in the care of preobese and obese patients is insufficient in $41 \%$ of cases. The number of obese patients per obesity specialist varies between 9000 and 100000 , which is unrealistically high. The survey suggested the establishment of obesity management centres in each country. At present, the number of inhabitants per obesity centre ranges from 1 million to 16 million. This is evidently not satisfactory. The survey also revealed a lack of both primary care and specialized health care in obesity management.

\section{Children}

Specific measures targeted at children are very important. Parents function as adult role models, and they have the main responsibility to take such actions. However, encouragement from the school, health services or day-care system must be given as well. A multidisciplinary approach with family therapy has proven successful in treating obese children. In Malmö, Sweden, a team with a physician, a nurse, a therapist, a dietician, a coach and an information officer has been established and promising results have already been produced.

In England it has been proposed that schools should introduce at least $1 \mathrm{~h}$ of mandatory physical activity per day. The current level of $2 \mathrm{~h}$ per week is far from enough. However, the content is important. Too much emphasis on vigorous exercise and evaluation of performance may discourage overweight children from increasing their physical activity.

\section{Surgery}

Promising long-term results on weight maintenance with surgical treatment have been produced in the Swedish Obesity Study (SOS). Also in Sweden, a recent review report from the Swedish Council on Technology Assessment in Health concluded that surgical treatment of obesity produced the best long-term results on weight maintenance (12). Surgery should, however, not be considered unless other treatment attempts have failed, and only for subjects with a BMI $>40 \mathrm{~kg} \mathrm{~m}^{-2}$.

\section{Result of the conference}

On 2 December 2002, the Council of the EU adopted a number of conclusions on obesity put forward by the Danish European Union Presidency. This was a very positive result of this conference and the first demonstrable sign that the conference made a difference. The conclusions were as follows. The Council:

- emphasizes its great concern about the serious health, social and economic impact of the increasing prevalence of overweight and obesity in individuals, particularly children, and in the European Community

- refers to scientific results showing that obesity is the major cause of a range of serious associated diseases, indicating that $15 \%$ of children and adolescents in Europe are suffering from obesity, and that this number will increase dramatically in many member states unless appropriate action is taken

- refers to the focus which the EU Conference on Obesity in Copenhagen, September 2002, put on the multiple problems caused by obesity, and the urgent request from leading international experts to act as quickly as possible on the basis of the existing documentation, simultaneously with the gathering of new knowledge

- underlines the need, in preventing and responding to the problems resulting from obesity, to take a cross-sectoral approach, including, inter alia, the health, social, food, educational, cultural and transport sectors.

Furthermore, the Council invites the member states to take account in their national public health policies of the need to address the issue of obesity.

Finally, the Council invites the commission to:

- reinforce its efforts to prevent and combat obesity

- support the member states in their efforts to prevent and manage obesity, taking into account the potential risk of eating disorders, particularly by developing innovative measures and approaches concerning nutrition and physical activity

- continue to strengthen the research on obesity

- ensure that prevention of obesity is taken into account in all relevant Community policies and, in particular, in the framework of the programme 
of Community action in the field of public health (2003-2008).

\section{Conclusion}

Obesity is increasing all over Europe, closely following the trend in the USA. This obesity epidemic, which is now also emerging in children, has led to a similar rise in type II diabetes and other major physical and psychosocial problems. The burden on health-care budgets is becoming significant. Therefore, actions are needed now. Obesity should be tackled through both prevention and treatment, and children should be given high priority. A change in environment and behaviour to promote healthy diet and exercise habits is necessary. Public health programmes, differentiated taxes on foods and drinks, collaboration between the food industry and health communities, training of health professionals, establishment of obesity management centres, and the use of family therapy, are all means that can work together to reduce the prevalence of obesity.

\section{References}

1. Obesity: Preventing and managing the global epidemic. Report of a WHO consultation, WHO Technical Report Series 894. Geneva: World Health Organization; 2000.

2. International Obesity Task Force and European Association for the Study of Obesity Task Forces. Obesity in Europe - the case for action. Position Paper 2002 (www.iotf.org)

3. Cole TJ, Bellizzi MC, Flegal KM, Dietz WH. Establishing a standard definition for child overweight and obesity worldwide: international survey. $\mathrm{Br}$ Med J 2000; 320: 1-6.

4. Raben A, Basse K, Rahbek AH, et al. BMI prevalence underestimated by $50 \%$ by using self-reported data on weight and height. Int J Obes Relat Metab Disord 2002; 26(Suppl 1): S12.

5. Hu FB, Manson JE, Stampfer MJ, et al. Diet, lifestyle, and the risk of type 2 diabetes mellitus in women. $\mathrm{N}$ Engl J Med 2001 Sep 13; 345: 790-7.

6. Passenger Transport Survey 1998-1999 (Virpi Pastinen, Viatek Ltd). Publications of the Ministry of Transport and Communications 43/99. Helsinki: Ministry of Transport and Communication; 1999 (in Finnish with English abstract).

7. Martinez-Gonzales MA, Martinez JA, Hu FB, et al. Physical inactivity, sedentary lifestyle and obesity in the European Union. Int J Obes 1999; 23: 1192-201.

8. Raben A, Vasilaras TH, Møller AC, Astrup A. Effect of 10 weeks' intake of sucrose vs artificial sweeteners on $a d$ libitum food intake and body weight in overweight subjects. Am J Clin Nutr 2002; 76: 721-9.

9. Nielsen SJ, Siega-Riz AM, Popkin BM. Trends in energy intake in US between 1977 and 1996: similar shifts seen across age groups. Obes Res 2002; 10: 370-8.

10. Astrup A, Buemann B, Flint A, Raben A. Low-fat diets and energy balance: how does the evidence stand in 2002? Proc Nutr Soc 2002; 61: 299-309.

11. Innocenti Declaration. On the protection, promotion and support of breast-feeding. World Alliance for Breastfeeding Action. WHO/UNICEF Meeting, 1990 (http://www.waba.org.br/inno.htm)

12. SBU Report from the Swedish Council on Technology Assessment in Health Care. Obesity - problems and interventions. A systematic review. Report No. 160. 2002. ISBN 91-87890-78-X. Stockholm: SBU.

\footnotetext{
Anne Raben

Department of Human Nutrition

Centre for Advance Food Studies

The Royal Veterinary and Agricultural University

30 Rolighedsvej

DK-1958 Frederiksberg C

Denmark

E-mail: ar@kvl.dk
} 